\title{
Screening of 31 genes involved in monogenic forms of obesity in 23 Pakistani probands with early-onset childhood obesity: a case report
}

Robina Khan Niazi ${ }^{1,2,34+}$, Anette Prior Gjesing ${ }^{2 *}$ D , Mette Hollensted ${ }^{2}$, Christian Theil Have ${ }^{2}$, Dmitrii Borisevich², Niels Grarup ${ }^{2}$, Oluf Pedersen², Asmat Ullah ${ }^{3,5}$, Gulbin Shahid ${ }^{4}$, Ifrah Shafqat ${ }^{1}$, Asma Gul ${ }^{1}$ and Torben Hansen ${ }^{2}$

\begin{abstract}
Background: Consanguine families display a high degree of homozygosity which increases the risk of family members suffering from autosomal recessive disorders. Thus, homozygous mutations in monogenic obesity genes may be a more frequent cause of childhood obesity in a consanguineous population.

Methods: We identified 23 probands from 23 Pakistani families displaying autosomal recessive obesity. We have previously excluded mutations in MC4R, LEP and LEPR in all probands. Using a chip-based, target-region capture array, 31 genes involved in monogenic forms of obesity, were screened in all probands.

Results: We identified 31 rare non-synonymous possibly pathogenic variants (28 missense and three nonsense) within the 31 selected genes. All variants were heterozygous, thus no homozygous pathogenic variants were found. Two of the rare heterozygous nonsense variants identified ( $p . R 75 X$ and p.R481X) were found in BBS9 within one proband, suggesting that obesity is caused by compound heterozygosity. Sequencing of the parents supported the compound heterozygous nature of obesity as each parent was carrying one of the variants. Subsequent clinical investigation strongly indicated that the proband had Bardet-Biedl syndrome.
\end{abstract}

Conclusions: Mutation screening in 31 genes among probands with severe early-onset obesity from Pakistani families did not reveal the presence of homozygous obesity causing variants. However, a compound heterozygote carrier of BBS9 mutations was identified, indicating that compound heterozygosity must not be overlooked when investigating the genetic etiology of severe childhood obesity in populations with a high degree of consanguinity.

Keywords: Autosomal recessive, Bardet-Biedl syndrome 9, Compound heterozygous, Early-onset obesity, Monogenic obesity, Pakistani families, Consanguinity

\section{Background}

Worldwide, the prevalence of obesity has risen more than tenfold during the past four decades and approximately124 million children and adults, aged five to 19 years old, were obese in 2016 [1]. Obesity is one of the major risk factors for metabolic syndrome, including

\footnotetext{
* Correspondence: anette.gjesing@sund.ku.dk

${ }^{\dagger}$ Robina Khan Niazi and Anette Prior Gjesing contributed equally to this work.

${ }^{2}$ Novo Nordisk Foundation Center for Basic Metabolic Research, Faculty of Health and Medical Sciences, University of Copenhagen, Copenhagen, Denmark

Full list of author information is available at the end of the article
}

arterial hypertension, cardiovascular disease, diabetes mellitus, dyslipidemia and cancer [2,3]. The etiology of obesity comprises both environmental and genetic factors, with a heritability of body mass index (BMI) between 40 to $70 \%[4,5]$.

In rare monogenic forms of obesity, disruption of a single gene is the cause obesity and individuals typically display severe early-onset obesity along with hyperphagia and endocrine disorders [6, 7]. Most of the causative proteins in monogenic forms of obesity are acting in the hypothalamic leptin-melanocortin signalling pathway,

(c) The Author(s). 2019 Open Access This article is distributed under the terms of the Creative Commons Attribution 4.0 International License (http://creativecommons.org/licenses/by/4.0/), which permits unrestricted use, distribution, and reproduction in any medium, provided you give appropriate credit to the original author(s) and the source, provide a link to the Creative Commons license, and indicate if changes were made. The Creative Commons Public Domain Dedication waiver (http://creativecommons.org/publicdomain/zero/1.0/) applies to the data made available in this article, unless otherwise stated. 
which is essential for the regulation of food intake, body weight and energy regulation $[8,9]$.

Generally, mutations in leptin $(L E P)$, the leptin receptor (LEPR) and the melanocortin 4 receptor $(M C 4 R)$ represent the most common cause of monogenic forms of obesity and mutations within these genes have been demonstrated to cause childhood morbid obesity in probands of various ethnicities [1014]. Yet, less than 5\% of cases are explained by variants in these genes in out-bred populations [15] and possibly upto $30 \%$ in a consanguineous Pakistani population $[12,16]$.

Other genes are involved in the melanocortin signalling pathway and many of these have also been implicated in monogenic forms of obesity, including $P O M C$, PCSK, SIM1, BDNF, NTRK2, SH2B1 and MRAP [6].

The most distinct monogenic syndromic forms of obesity are characterized by severe early-onset obesity combined with other features, including alterations in hormone levels or dysmorphic characteristics, such as organ developmental deformities [17, 18]. Although a few syndromic forms of obesity, such as Alström syndrome, are not characterized by developmental delay [19], several are linked with varying degrees of mental retardation, including Prader-Willi syndrome [19], SIM1 syndrome [20] and WAGR syndrome [21]. Moreover, Bardet-Biedl syndrome (BBS), fragile $\mathrm{X}$ syndrome, Cohen syndrome and Albright's Hereditary Osteodystrophy are all pleotropic disorders linked to developmental delay [19]. These rare syndromic forms of obesity may be instigated by either autosomal, X-linked chromosomal abnormalities or distinct genetic defects $[18,22,23]$.

Worldwide, consanguineous marriage have been practiced in many populations for several generations due to social and economic benefits [24-26] and the Pakistani population has the highest rate of consanguinity in the world, with frequencies of $60-76 \%$ [27, 28]. In families with a known history of consanguineous marriages, the degree of homozygosity in family members is $11 \%$ on average and consanguinity thereby increases the risk of family members suffering from autosomal deleterious recessive disorders [28]. Thus genetic screening of consanguineous families with severe early-onset obesity, constitutes a powerful method of identifying causal homozygous mutations and has enabled the identification of rare damaging variants in e.g. $L E P, L E P R$ and MC4R [10, 11, 29].

In the current study, we performed genetic screening of 31 genes previously demonstrated to be involved in childhood obesity in 23 unrelated probands from Pakistani families with severe early-onset obesity segregating as an autosomal recessive trait. We have previously excluded mutations in $L E P, L E P R$ and $M C 4 R$ as causative mutations in all probands.

\section{Methods}

\section{Study population}

Twenty-three families originating from different regions of Pakistan were recruited for the current study. These families were examined at Children Hospital, Pakistan Institute of Medical Sciences (PIMS), Islamabad. Patients were recruited between November 2015 and April 2017. Eleven families had known consanguineous marriages. Selection of families was based on four parameters, including: 1) BMI of probands $\geq 30 \mathrm{~kg} / \mathrm{m}^{2}$ or BMI standard deviation score (SDS) $\geq 3$; 2) Probands displaying obesity onset before five years of age; 3 ) Parents of the probands having a $\mathrm{BMI} \leq 25 \mathrm{~kg} / \mathrm{m}^{2}$, consistent with an autosomal recessive mode of inheritance and 4) Probands not carrying homozygous $L E P, L E P R$ and $M C 4 R$ mutations. In families with several affected individuals, the patient having the most severe phenotype was selected for sequencing (Table 1). Probands from all 23 families in addition to family members from OB1 (OB1-2 and OB1-4), OB2 (OB2-1, OB2-2 and OB2-6), OB8 (OB8-1 and OB8-2) and $\mathrm{OB} 15$ (OB15-1 and OB15-2) underwent targeted resequencing (Fig. 1).

\section{Clinical characterization}

Height $(\mathrm{cm})$ and waist circumference $(\mathrm{cm})$ were measured with non-extendable plastic tape with the participant standing in a straight position and without shoes. Using a digital scale, weight $(\mathrm{kg})$ was measured to the nearest $1.0 \mathrm{~kg}$ with the participant wearing light clothes and no shoes. Based on interviews, information about the age at obesity onset, other major chronic disease or metabolic diseases (if any) segregating in the family, eating habits and physical activity were collected along with obesity-related co-morbidities. BMI was calculated as the weight in kilograms divided by the square of the height in meters $\left(\mathrm{kg} / \mathrm{m}^{2}\right)$ and a BMI standard deviation score (SDS) was calculated based on a World Health Organization (WHO) reference population [30] using

Table 1 Clinical presentation of probands

\begin{tabular}{ll}
\hline Trait & Probands \\
\hline Gender (M/F) & $13 / 10$ \\
Age at enrolment (years) & $16.6(6.81)$ \\
Age of obesity onset (years) & Below the age of 5 years \\
Height (cm) & $149.8(24.4)$ \\
Weight (kg) & $82.8(26.0)$ \\
BMI (kg/m²) & $36.5(8.81)$ \\
BMI SDS & $3.20(1.24)$ \\
Waist circumference (cm) & $102.0(14.7)$ \\
Consanguine family (yes/no) & $11 / 12$ \\
Family history of obesity (yes/no) & $14 / 9$ \\
\hline
\end{tabular}

Data is presented as neither number of individuals or as mean (SD) 


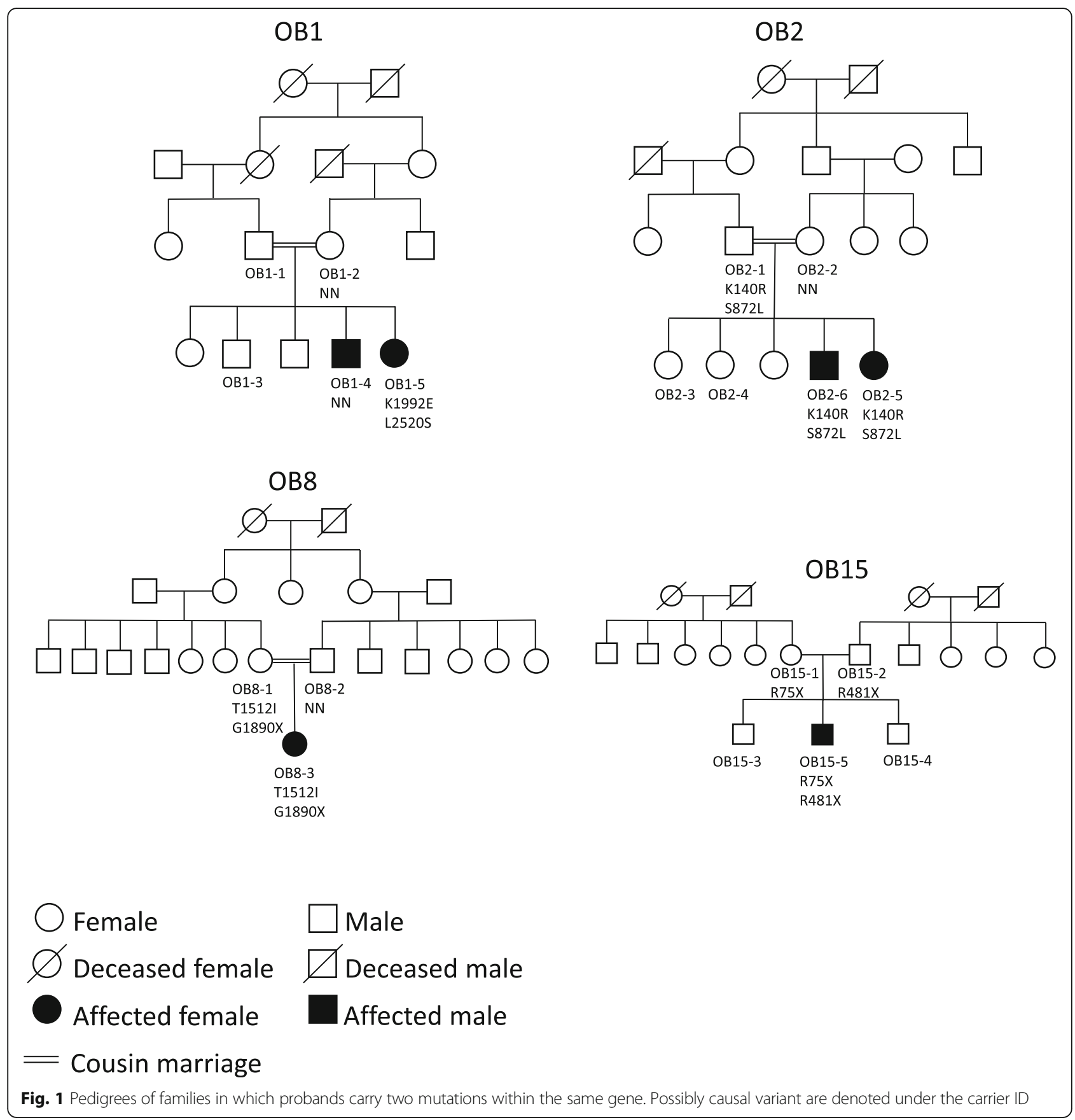

the LMS method [31]. The clinical characteristics of the study participants are presented in Table 1 and Additional file 1.

For comparison of inbreeding coefficient, we used information from 298 Danish individuals from 61 families which have previously been described [32].

\section{Genomic DNA extraction}

Approximately 3-5 $\mathrm{ml}$ venous blood samples from 31 affected and 79 unaffected family members were collected in the non-fasting state in $8.5 \mathrm{ml}$ vacutainer tubes (BD
Vacutainer ${ }^{\bullet}$ ACD, Franklin Lakes NJ, USA). Following the standard phenol-chloroform method [33] and using QIAamp DNA Mini Kit (Qiagen, Germany), the genomic DNA was extracted.

\section{Targeted region array design}

A chip-based customized nucleotide probe was used for capturing genomic DNA of the coding regions of 31 selected genes involved in monogenic forms of obesity (ADCY3, ALMS1, ARL6, BBS1, BBS2, BBS4, BBS5, BBS7, $B B S 9, \quad B B S 10, \quad B B S 12, \quad B D N F, \quad C C D C 28 B, C E P 290$, 
CREBBP, EP300, GNAS, IER3IP1, MKKS, MKS1, MRAP2, NTRK2, PCSK1, PHF6, POMC, SH2B1, SIM1, TMEM67, TRIM32, TTC8 and VPS13B). Methods for DNA extraction, target region capture and next generation sequencing have previously been described [34].

The final captured DNA libraries were sequenced according to the manufacturer's standard cluster generation and sequencing protocols, using the Illumina HiSeq2000 Analyzers as paired-end 90 base pair reads.

\section{Genotyping}

Illumina Infinium Human CoreExomeBeadChip (CoreExomeChip) genotyping was performed in 104 individuals from 23 families of Pakistani origin and 298 individuals from 61 families of Danish origin using Illumina's HiScan system at the laboratory facilities of the Novo Nordisk Foundation Center for Basic Metabolic Research at Symbion, Copenhagen, Denmark. The pipeline and quality control protocol has previously been described for Pakistani participants [16] and for Danish participants [32].

\section{Variant selection}

Variants were considered possibly pathogenic if: 1) they were variants with minor allele frequency (MAF) $<0.1 \%$ in publically available databases $[35,36]$; 2) coding nonsynonymous variants or splice variants located up to 3 nucleotides into the intron/exon boundary; 3) having minimum depths of $20 \mathrm{x}$ and 4) a allelic ratio between 0.4-0.6 for heterozygous mutations.

Families were recruited based on the presence of affected children from non-affected parents both from families with known and without known consanguinity. Thus, three different genetic inheritance patterns may likely exist in the recruited families: 1) recessive, 2) compound heterozygotes and 3) heterozygous de novo heritance. The latter mode of inheritance was not considered despite the fact that causal heterozygous mutations have been suggested for some of the selected genes [37-40], as authentication of such potentially causal heterozygous de novo mutations is complex and sequencing information from both parents is warranted.

Pathogenicity of the variants were evaluated using in silico annotation tools [41-43] especially using Combined Annotation Dependent Depletion (CADD) score where a PHRED-scaled CADD score above 10 predicts pathogenicity in top 10 percentile of all variants and a score above 20 predicts the top 1 percentile [44].

\section{Statistical analysis}

Relatedness analysis was calculated as an inbreeding coefficient which is based on the genotyping of included individuals. This estimates the probability of a random locus in related individuals being identical by descent. This was calculated using the "het" command using PLINK [45]. Inbreeding coefficients was compared between individuals from consanguine Pakistani families, non-consanguine Pakistani families and Danish outbreed families using a student's t-test in R software (version 3.2.3; R Foundation for Statistical Computing, Boston, MA, USA).

\section{Results}

We investigated the level of relatedness in families with and without known consanguinity using the inbreeding coefficient. This estimates the probability of a random locus in related individuals being identical by descent. We found that families with known consanguinity had a mean inbreeding coefficient of 5.6\% (SD: 4.5) in contrast to Pakistani families without consanguinity having a mean inbreeding coefficient of 3.2\% (SD: 3.0$)(p=0.003)$. However, when comparing non-consanguine Pakistani families to Danish outbred families having an inbreeding coefficient of $-1.02 \%$ (SD: 0.65 ), the inbreeding coefficient of non-consanguine Pakistani families was still significantly higher $\left(p=4 * 10^{-13}\right)$. Thus, recessive inheritance-patterns are likely to exist in Pakistani families with both known and unknown consanguinity.

Thirty-one genes were selected based on their known causal involvement in childhood obesity and among the probands we identified a total of 31variants located in ALMS1, BBS7, BBS9, BBS10, CREBPB, EP300, PCSK1, $P O M C$ and $V S P 13 B$ fulfilling the criteria for being possibly pathogenic (28 missense and three nonsense) (Additional file 2).

Due to the large number of consanguineous families and the high level of relatedness in families without known consanguinity, we searched for homozygous recessive variants. Yet, no homozygous pathogenic carriers were found.

Subsequently we investigated the presence of probands carrying two heterozygous mutations within the same gene and found four potentially compound heterozygous probands: 1) OB1-5 carrying the p.K1992E and the p.I2520S in ALMS1; 2) OB2-5 carrying the p.S872 L and p.K140R in CEP290; 3) OB8-3 carrying the p.T1512I and p.G1890X also in CEP290; and 4) OB15-5 carrying the p.R75X and p.R481X in BBS9 (Table 2).

OB1-5, carrying two rare missense variants in ALMS1, displays hyperphagia in addition to severe early-onset obesity. Sequencing of the mother (OB1-2) and the affected sibling $\mathrm{OB} 1-4)$ revealed that the variants found in the proband (OB1-5) was not carried by the affected sibling, nor was the mother a carrier of any of the two ALMS1 variants found in proband (Fig. 1). In addition, the affected individuals in OB1 did not present with the 
Table 2 Mutation type and phenotypic presentation in probands carrying two heterozygous variants within the same gene

\begin{tabular}{|c|c|c|c|c|c|c|c|}
\hline $\begin{array}{l}\text { Family } \\
\text { ID }\end{array}$ & $\begin{array}{l}\text { Proband } \\
\text { ID }\end{array}$ & Gene & $\begin{array}{l}\text { Identified } \\
\text { variants }\end{array}$ & Primary phenotype of patient & $\begin{array}{l}\text { Secondary } \\
\text { phenotypes of } \\
\text { patients }\end{array}$ & $\begin{array}{l}\text { Phenotypic characteristic of } \\
\text { patients with syndromes } \\
\text { related to investigated gene }\end{array}$ & $\begin{array}{l}\text { Mutations co- } \\
\text { segregation } \\
\text { with phenotype }\end{array}$ \\
\hline $\mathrm{OB} 1$ & OB1.5 & ALMS1 & $\begin{array}{l}\text { p.K1992E } \\
\text { p.L2520S }\end{array}$ & Hyperphagia & NA & $\begin{array}{l}\text { ALMS: } \\
\text { retinal degeneration, hearing } \\
\text { loss, diabetes mellitus, } \\
\text { dilated cardiomyopathy, } \\
\text { urological dysfunction, } \\
\text { pulmonary, hepatic, renal failure }\end{array}$ & No \\
\hline OB2 & OB2-5 & CEP290 & $\begin{array}{l}\text { p.S872L } \\
\text { p.K140R }\end{array}$ & Hyperphagia, Hypertension & NA & \multirow{2}{*}{$\begin{array}{l}\text { Joubert syndrome: } \\
\text { brain abnormalities, molar } \\
\text { tooth sign, hypotonia, } \\
\text { ataxia, hyperpneaorapnea, } \\
\text { ocular motor apraxia }\end{array}$} & No \\
\hline OB8 & OB8-3 & & $\begin{array}{l}\text { p.T15121 } \\
\text { p.G1890X }\end{array}$ & Dyslipidemia & NA & & No \\
\hline OB15 & OB15-5 & BBS9 & $\begin{array}{l}\text { p.R75X } \\
\text { p.R481X }\end{array}$ & $\begin{array}{l}\text { Hypogonadism, } \\
\text { Mental retardation, Obesity, } \\
\text { Vision impairment. }\end{array}$ & $\begin{array}{l}\text { Speech impairment, } \\
\text { Hypertension. }\end{array}$ & $\begin{array}{l}\text { Bardet-bieldel syndrome: } \\
\text { obesity, polydactyly, renal } \\
\text { anomalies, retinopathy, } \\
\text { mental retardation }\end{array}$ & Yes \\
\hline
\end{tabular}

phenotypic characteristics of Alstrom syndrome such as retinal degeneration, hearing loss, diabetes mellitus, dilated cardiomyopathy (DCM), urological dysfunction, pulmonary, hepatic and renal failure. Thus, neither cosegregation nor phenotypic presentation suggests that the two variants found in OB1-5 in ALMS1 are causal for the childhood obesity in OB1.

The probands in family OB2 and OB8 are each having two mutations in CEP290. OB2-5 carried the p.K140R and p.S872 L missense mutations and the proband in OB8 (OB8-3) is carrying the p.T1512I missense mutation and the p.G1890X nonsense mutation. The functional prediction of the p.K140R variant based on the CADD score, indicate only a minor impaired functionality (CADD score:14.6, Table 2). This lack of presumed functionality is supported by the lack of clinical characteristic in OB2 of patients with CEP290 mutations such as retinal degeneration, hypogonadism, polydactyly, renal dysfunction and MR [46]. Subsequent sequencing of CEP290 in the parents (OB2-1 and OB2-2) and sibling (OB2-6) of OB2-5, revealed that both variants present in the proband were inherited from the father but not from the mother in whom none of the two variants were present (Table 2).

The p.G1890X variant found in OB8-3 has previously been found to cause Joubert syndrome-related disorders (JBTS) in a homozygous manner in a Turkish family [47]. The JBTS affects the central nervous system (brain and spinal cord), retina and kidney and it is inherited in autosomal recessive manner. Moreover, a high CADD scores was found for both the missense and nonsense variants (26.5 and 36, respectively) supporting a highly pathogenic nature of these two mutations. Yet, sequencing of CEP290 in the parents (OB8-1 and OB8-2) of proband OB8-3 showed that the variants found in OB8-3, both were inherited from the mother (Fig. 1). This lack of co-segregation was also supported by the proband (OB8-3) not displaying any of the symptoms characteristic of the syndromes related to CEP290 mutations such as JBTS, thus, we do not believe OB8-3 is suffering from CEP290 related obesity.

The probands in OB15 is carrying the two nonsense mutations p.R75X and p.R481X both very likely highly deleterious mutations. Patients with BBS caused by homozygous or compound heterozygous mutations in $B B S 9$ are characterized by obesity, polydactyly, renal anomalies, retinopathy and mental retardation. OB15-5 presents with a large number of the primary BBS phenotypes including hypogonadism, developmental delay with learning difficulties, speech- and vision- impairment in addition to severe childhood obesity. Moreover, sequencing of $B B S 9$ in the parents (OB15-1 and OB15-2) of OB15-5 revealed that p.R75X was inherited from the mother and p.R481X was inherited from the father. Therefore, the proband OB15-5 is likely a patient with BBS due to compound heterozygous mutations in BBS9.

\section{Discussion}

In the current study, targeted resequencing of the coding regions of 31 selected genes known to be involved in monogenic forms of obesity (excluding LEP, LEPR and $M C 4 R$ ) was performed in 23 probands from Pakistani families with severe early-onset obesity segregating as an autosomal recessive trait. One compound heterozygous proband was identified carrying two nonsense variants in BBS9/PTHB1 (p.R75X and p.R481X) in exon 3 and exon 14, respectively, causing BBS.

Homozygous and tri-allelic variants in $B B S$ genes have been reported to cause BBS phenotypes in Pakistani population [48-50], but no prior BBS9 compound heterozygous patients have been reported in non-consanguineous Pakistani families.

Bardet-Biedl syndrome protein complex (BBSome) is a central entity of ciliogenesis and it has 10 subunits from 
BBS1 to 10 [51]. BBS9, a99-kDa protein, is one of the component of the BBSome and it has a suggested role in associating other subunits [52]. Studies of BBS9 function in knock down mouse and zebra fish, have revealed its significant role in cilia biogenesis [53]. In our study, the identified variant p.R75X is positioned in the $\mathrm{N}$-terminal domain and the p.R481X is positioned in the C-terminal half of the PTHB1 protein. The full length BBS9 contains 887 amino acids, thus, termination of the protein after only 75 and 481 amino acids, respectively, is not surprisingly detrimental for the function of the protein due to non-sense mediated decay or production of truncated protein [54]. Hence, we believe that these loss-offunction mutations in BBS9 may be responsible for structural abnormality in cilia due to reduced integrity of BBSome proteins complex.

Previous studies examining the genetic causes of severe early-onset obesity in Pakistani families have mainly focused on a few genes most often linked to monogenic forms of obesity i.e. $L E P, L E P R$ and $M C 4 R$ [10, 12, 55-57], yet, more recently, a mutation screen of multiple genes was performed in 39 unrelated children with severe obesity from consanguineous Pakistani families [56]. The study included 21 of the 31 genes examined in the present study and was similar to our findings with no casual mutations in homozygous conditions identified [56]. The remaining ten genes (CCDC28B, CREBBP, EP300, IER3IP1, MRAP2, PHF6, SH2B1, TMEM67, VPS13B), selected in the present study were therefore, screened for the first time in Pakistani families with the aim of assessing the prevalence of damaging mutations conferring early-onset obesity. However, our findings indicate that mutations within the selected 31 genes are not a common cause of severe earlyonset obesity in the Pakistani population.

No personalized treatment approach has been identified for syndromic forms of obesity and the affected individuals are generally advised to follow current general treatment approaches, including increased physical activity, psychomotricity (activities which integrate cognitive, emotional and physical elements) and an energy restricted diet [6].

Four potential compound heterozygous probands were identified; however, we only claim the causal effect in one proband. Establishing pathogenicity of missense mutation is challenging and this even more so in the present Pakistani study population, as identified variants may be present in the unaffected background population but may not appear in any publically available databases which are most frequently based on Caucasian populations. However, in the present study, co-segregation analysis supported the likely causality of nonsense mutations in which pathogenicity is highly probable.

Our investigation of the relatedness between individuals in families with known consanguinity versus families without known consanguinity, clearly indicate that the fraction of genetic loci which show identity by descent within a family, are of considerable proportion even in families without known consanguinity from population where consanguinity is frequent. This strongly indicates that recessive disease mechanisms generally should be considered in families of Pakistani descent. Thus, whole exome sequencing or whole genome sequencing will likely be fruitful strategies to identify novel causal homozygous mutations in inbred populations.

\section{Conclusion}

Among 23 Pakistani families, mutations within 31 genes known to be involved in the development of obesity are not a cause of severe early-onset obesity. Yet, the present study identified one compound heterozygote patient with BBS, thus, the presence of compound heterozygous patients must not be overlooked in populations with a high degree of consanguinity.

\section{Additional files}

Additional file 1: Clinical information on 23 probands with early onset childhood obesity from 23 Pakistani families (DOCX 23 kb)

Additional file 2: List of identified rare variants among 23 Pakistani probands with early onset childhood obesity. (DOCX 26 kb)

\section{Abbreviations}

BBS9: Bardet-Biedl syndrome 9; BMI: Body mass index; LEP: Leptin; LEPR: Leptin-receptor; MAF: Minor allele frequency; MC4R: Melanocortin 4 receptor; PIMS: Pakistan Institute of Medical Sciences; SDS: Standard deviation score; WES: Whole exome sequencing

\section{Acknowledgements}

We would like to thank the patients and their family members for their involvement and cooperation in this study. We would also wish to thank A Forman, T. H. Lorentzen and G. J. Klavsen for laboratory assistance, G. Lademann for secretarial support and T.F. Toldsted and Camilla Verdich for grant management (all from Novo Nordisk Foundation Center for Basic Metabolic Research, Section of Metabolic Genetics, Faculty of Health and Medical Sciences, University of Copenhagen). Novo Nordisk Foundation Center for Basic Metabolic Research is an independent Research Center, based at the University of Copenhagen, Denmark and partially funded by an unconditional donation from the Novo Nordisk Foundation (www.cbmr.ku. dk) (Grant number NNF18CC0034900).

\section{Authors' contributions}

RKN, APG, MH, NG, OP, CTH, AG and TH contributed to the conception and design of the study. GS and RKN examined and performed the clinical evaluation of the patients in each family. RKN and IS made visits and did the sampling of the families. RKN prepared the genomic DNA samples, while AU provided assistance in preparation of genomic DNA samples. RKN, APG, MH, $\mathrm{DB}, \mathrm{CTH}$ and $\mathrm{TH}$ performed the analysis and did the interpretation of data. APG drafted the article. Literature search was performed by RKN, APG and $\mathrm{MH}$ and figures were prepared by RKN and APG. All authors critically revised the manuscript and contributed to the discussion. The final version of the paper was read and approved by all authors.

\section{Funding}

This study was partial funded by the Higher Education Commission (HEC) of Pakistan by awarding IRSIP (Grant No: 1-8/HEC/HRD/2017/17326, PIN: IRSIP 35 BMS 26) (RKN) and by the Danish Innovation Foundation and the Novo 
Nordisk Foundation (NNF15CC0018486 and NNF18CC0034900). The funders did not have any role in study design, data collection and analysis, decision to publish, or preparation of the manuscript.

\section{Availability of data and materials}

The datasets generated and/or analyzed during the current study are not publicly available due to limitations in the consent form (consent has been given to study severe early-onset obesity), but are available from the corresponding author on reasonable request.

\section{Ethics approval and consent to participate}

The current study protocol was conducted in accordance with the guidelines of the Helsinki Declaration. Informed consent forms were obtained from individuals aged 18 years or older, while informed consent for individuals $<18$ years of age was obtained from their parents or guardians. The current study protocol was approved by the local Ethical Committee with the name of 'Ethics Review Board (ERB) of Pakistan Institute of Medical Sciences (PIMS) at Shaheed Zulfiqar Ali Bhutto Medical University (SZABMU), Islamabad, Pakistan and the committee's reference number is No. F. 1-1/ 2015/ERB/SZABMU/-.

\section{Consent for publication}

Written informed consent was obtained from the patients or their parents for the publication of their clinical data and genetic data.

\section{Competing interests}

The authors declare that no conflicts interests.

\section{Author details}

${ }^{1}$ Department of Biological Sciences, International Islamic University, Islamabad, Pakistan. ${ }^{2}$ Novo Nordisk Foundation Center for Basic Metabolic Research, Faculty of Health and Medical Sciences, University of Copenhagen, Copenhagen, Denmark. ${ }^{3}$ Department of Biochemistry, Faculty of Biological Sciences, Quaid-i-Azam University, Islamabad, Pakistan. ${ }^{4}$ Children Hospital, Pakistan Institute of Medical Sciences (PIMS), Islamabad, Pakistan. ${ }^{5}$ Department of Molecular Biology, Shaheed Zulfiqar Ali Bhutto Medical University, PIMS, Islamabad, Pakistan.

Received: 18 March 2019 Accepted: 29 August 2019 Published online: 05 September 2019

\section{References}

1. World Health Organization. http://www.who.int/mediacentre/news/ releases/2017/increase-childhood-obesity/en/. Accesed on 20.10.17.

2. Nguyen NT, Magno CP, Lane KT, Hinojosa MW, Lane JS. Association of hypertension, diabetes, dyslipidemia, and metabolic syndrome with obesity: findings from the national health and nutrition examination survey, 1999 to 2004. J Am Coll Surg. 2008;207(6):928-34.

3. Winter Y, Sankowski R, Back T: Chapter two - genetic determinants of obesity and related vascular diseases. In: Vitamins \& Hormones. Edited by Litwack G, vol. 91: Academic Press; 2013. 29-48.

4. Stunkard AJ, Foch T, Hrubec Z. A twin study of human obesity. Jama. 1986; 256(1):51-4.

5. Maes HHM, Neale MC, Eaves $L$. Genetic and environmental factors in relative body weight and human adiposity. Behav Genet. 1997;27(4):325-51.

6. Huvenne H, Dubern B, Clément K, Poitou C. Rare genetic forms of obesity: clinical approach and current treatments in 2016. Obes Facts. 2016;9(3):15873.

7. Gale SM, Castracane VD, Mantzoros CS. Energy homeostasis, obesity and eating disorders: recent advances in endocrinology. J Nutr. 2004;134(2):2958

8. Farooqi IS, O'Rahilly S. Leptin: a pivotal regulator of human energy homeostasis. Am J Clin Nutr. 2009:89(3):980s-4s.

9. Walley AJ, Asher JE, Froguel P. The genetic contribution to non-syndromic human obesity. Nat Rev Genet. 2009;10(7):431-42.

10. Montague CT, Farooqi IS, Whitehead JP, Soos MA, Rau H, Wareham NJ, et al. Congenital leptin deficiency is associated with severe early-onset obesity in humans. Nat. 1997:387(6636):903-8.

11. Clement K, Vaisse C, Lahlou N, Cabrol S, Pelloux V, Cassuto D, et al. A mutation in the human leptin receptor gene causes obesity and pituitary dysfunction. Nat. 1998;392(6674):398-401.
12. Saeed S, Bonnefond A, Manzoor J, Shabir F, Ayesha H, Philippe J, et al. Genetic variants in LEP, LEPR, and MC4R explain 30\% of severe obesity in children from a consanguineous population. Obesity. 2015;23(8):1687-95.

13. Stutzmann F, Tan K, Vatin V, Dina C, Jouret B, Tichet J, et al. Prevalence of melanocortin-4 receptor deficiency in Europeans and their age-dependent penetrance in multigenerational pedigrees. Diabetes. 2008;57(9):2511-8.

14. Farooqi IS, Wangensteen T, Collins S, Kimber W, Matarese G, Keogh JM, et al. Clinical and molecular genetic spectrum of congenital deficiency of the leptin receptor. New Engl J of Med. 2007;356(3):237-47.

15. Saeed S, Bonnefond A, Tamanini F, Mirza MU, Manzoor J, Janjua QM, et al. Loss-of-function mutations in ADCY3 cause monogenic severe obesity. Nat Genet. 2018;50(2):175-9.

16. Niazi RK, Gjesing AP, Hollensted M, Have CT, Grarup N, Pedersen O, et al. Identification of novel LEPR mutations in Pakistani families with morbid childhood obesity. BMC Med Genet. 2018;19(1):199-x.

17. Bell CG, Walley AJ, Froguel P. The genetics of human obesity. Nat Rev Genet. 2005:6(3):221-34

18. Larder R, Lim CT, Coll AP: Chapter 6 - Genetic aspects of human obesity. In: Handbook of Clinical Neurology. Edited by Fliers E, Korbonits M, Romijn JA, vol. 124: Elsevier; 2014. 93-106.

19. Faroogi IS, O'Rahilly S. In: Jameson JL, De Groot LJ, de Kretser DM, Giudice LC, Grossman AB, Melmed S, et al., editors. Chapter 28 - Genetic Syndromes Associated with Obesity. In: Endocrinology: Adult and Pediatric (Seventh Edition). Philadelphia: W.B: Saunders; 2016. p. 491-7.

20. Faivre L, Cormier-Daire V, Lapierre J, Colleaux L, Jacquemont S, Genevieve D, et al. Deletion of the SIM1 gene $(6 q 16.2)$ in a patient with a Prader-Willi-like phenotype. J of Med Genet. 2002;39(8):594-6.

21. Rose EA, Glaser $T$, Jones $C$, Smith $C L$, Lewis WH, Call KM, et al. Complete physical map of the WAGR region of 11 p13 localizes a candidate Wilms' tumor gene. Cell. 1990;60(3):495-508.

22. Singh RK, Kumar P, Mahalingam K. Molecular genetics of human obesity: a comprehensive review. C R Biol. 2017;340(2):87-108.

23. O'Rahilly S, Farooqi IS, Yeo GSH, Challis BG. Minireview: human obesity-lessons from monogenic disorders. Endocrinology. 2003;144(9):3757-64.

24. Bittles $\mathrm{AH}$. Consanguinity and its relevance to clinical genetics. Clin Genet. 2001;60(2):89-98.

25. Ahmad WIU. Reflections on the consanguinity and birth outcome debate. J Public Health Med. 1994;16(4):423-8.

26. Audinarayana N, Krishnamoorthy S. Contribution of social and cultural factors to the decline in consanguinity in South India. Soc Biol. 2000;47(3-4): 189-200.

27. Hashmi MA. Frequency of consanguinity and its effect on congenital malformation--a hospital based study. J Pak Med Assoc. 1997;47(3):75-8.

28. Woods CG, Cox J, Springell K, Hampshire DJ, Mohamed MD, McKibbin M, et al. Quantification of homozygosity in consanguineous individuals with autosomal recessive disease. Am J Hum Genet. 2006;78(5):889-96.

29. Yeo GS, Farooqi IS, Aminian S, Halsall DJ, Stanhope RG, O'Rahilly S. A frameshift mutation in MC4R associated with dominantly inherited human obesity. Nat Genet. 1998;20(2):111-2.

30. Butte NF, Garza C, de Onis M. Evaluation of the feasibility of international growth standards for school-aged children and adolescents. J Nutr. 2007; 137(1):153-7.

31. Cole TJ, Green PJ. Smoothing reference centile curves: the Ims method and penalized likelihood. Stat Med. 1992;11(10):1305-19.

32. Gjesing AP, Ribel-Madsen $R$, Harder MN, Eiberg $H$, Grarup $N$, Jorgensen $T$, et al. Genetic and phenotypic correlations between surrogate measures of insulin release obtained from OGTT data. Diabetologia. 2015;58(5):1006-12.

33. Sambrook J, Russell DW. Molecular cloning: a laboratory manual; preparation and analysis of eukaryotic genomic DNA 3rd edition. New York: Cold Spring Harbor Laboratory Press; 2001.

34. Gao R, Liu Y, Gjesing AP, Hollensted M, Wan X, He S, et al. Evaluation of a target region capture sequencing platform using monogenic diabetes as a study-model. BMC Genet. 2014;15(1):13-x.

35. Lek M, Karczewski KJ, Minikel EV, Samocha KE, Banks E, Fennell T, et al. Analysis of protein-coding genetic variation in 60,706 humans. Nat. 2016; 536(7616):285-91.

36. Auton A, Brooks LD, Durbin RM, Garrison EP, Kang HM, Korbel JO, et al. A global reference for human genetic variation. Nat. 2015;526(7571):68-74.

37. Creemers JW, Choquet H, Stijnen P, Vatin V, Pigeyre M, Beckers S, et al. Heterozygous mutations causing partial prohormone convertase 1 deficiency contribute to human obesity. Diabetes. 2012;61(2):383-90. 
38. Stijnen P, Ramos-Molina B, O'Rahilly S, Creemers JW. PCSK1 mutations and human endocrinopathies: from obesity to gastrointestinal disorders. Endocr Rev. 2016;37(4):347-71.

39. Grarup N, Moltke I, Andersen MK, Dalby M, Vitting-Seerup K, Kern T, et al. Loss-of-function variants in $A D C Y 3$ increase risk of obesity and type 2 diabetes. Nat Genet. 2018;50(2):172-4.

40. Marshall JD, Muller J, Collin GB, Milan G, Kingsmore SF, Dinwiddie D, et al. Alstrom syndrome: mutation spectrum of ALMS1. Hum Mutat. 2015;36(7): 660-8.

41. Kumar P, Henikoff S, Ng PC. Predicting the effects of coding nonsynonymous variants on protein function using the SIFT algorithm. Nat Protoc. 2009;4(7):1073-81.

42. Adzhubei I, Jordan DM, Sunyaev SR. Predicting functional effect of human missense mutations using PolyPhen-2. Curr Protoc Hum Genet. 2013; Chapter 7Unit7.20

43. Schwarz JM, Rodelsperger C, Schuelke M, Seelow D. MutationTaster evaluates disease-causing potential of sequence alterations. Nat Methods. 2010;7(8):575-6

44. Kircher M, Witten DM, Jain P, O'Roak BJ, Cooper GM, Shendure J. A general framework for estimating the relative pathogenicity of human genetic variants. Nat Genet. 2014;46(3):310-5.

45. Purcell S, Neale B, Todd-Brown K, Thomas L, Ferreira MA, Bender D, et al. PLINK: a tool set for whole-genome association and population-based linkage analyses. Am J Hum Genet. 2007;81(3):559-75.

46. Coppieters F, Lefever S, Leroy BP, De Baere E. CEP290, a gene with many faces: mutation overview and presentation of CEP290base. Hum Mutat. 2010;31(10):1097-108.

47. Valente EM, Silhavy JL, Brancati F, Barrano G, Krishnaswami SR, Castori M, et al. Mutations in CEP290, which encodes a centrosomal protein, cause pleiotropic forms of Joubert syndrome. Nat Genet. 2006;38(6):623-5.

48. Ullah A, Umair M, Yousaf M, Khan SA, Nazim-Ud-Din M, Shah K, et al. Sequence variants in four genes underlying Bardet-Biedl syndrome in consanguineous families. Mol Vis. 2017;23(1):482-94.

49. Ullah A, Khalid M, Umair M, Khan SA, Bilal M, Khan S, et al. Novel sequence variants in the MKKS gene cause Bardet-Biedl syndrome with intra- and inter-familial variable phenotypes. Congenit Anom (Kyoto). 2018;58(5):173-5.

50. Khan MA, Mohan S, Zubair M, Windpassinger C. Homozygosity mapping identified a novel protein truncating mutation (p.Ser100Leufs*24) of the BBS9 gene in a consanguineous Pakistani family with Bardet Biedl syndrome. BMC Med Genet. 2016;17(1):10-X.

51. Singla V, Reiter JF. The primary cilium as the cell's antenna: signaling at a sensory organelle. Sci. 2006;313(5787):629-33.

52. Nachury MV, Loktev AV, Zhang Q, Westlake CJ, Peranen J, Merdes A, et al. A core complex of BBS proteins cooperates with the GTPase Rab8 to promote ciliary membrane biogenesis. Cell. 2007;129(6):1201-13.

53. Veleri S, Bishop K, Dalle Nogare DE, English MA, Foskett TJ, Chitnis A, et al. Knockdown of Bardet-Biedl syndrome gene BBS9/PTHB1 leads to cilia defects. PLoS One. 2012;7(3):e34389.

54. Maquat LE. Defects in RNA splicing and the consequence of shortened translational reading frames. Am J Hum Genet. 1996;59(2):279-86.

55. Fatima W, Shahid A, Imran M, Manzoor J, Hasnain S, Rana S, et al. Leptin deficiency and leptin gene mutations in obese children from Pakistan. Int J Pediatr Obes. 2011;6(5-6):419-27.

56. Saeed S, Bonnefond A, Manzoor J, Philippe J, Durand E, Arshad M, et al. Novel LEPR mutations in obese Pakistani children identified by PCR-based enrichment and next generation sequencing. Obesity. 2014;22(4):1112-7.

57. Saeed S, Bech PR, Hafeez T, Alam R, Falchi M, Ghatei MA, et al. Changes in levels of peripheral hormones controlling appetite are inconsistent with hyperphagia in leptin-deficient subjects. Endocrine. 2014;45(3):401-8.

\section{Publisher's Note}

Springer Nature remains neutral with regard to jurisdictional claims in published maps and institutional affiliations.

Ready to submit your research? Choose BMC and benefit from:

- fast, convenient online submission

- thorough peer review by experienced researchers in your field

- rapid publication on acceptance

- support for research data, including large and complex data types

- gold Open Access which fosters wider collaboration and increased citations

- maximum visibility for your research: over $100 \mathrm{M}$ website views per year

At $\mathrm{BMC}$, research is always in progress.

Learn more biomedcentral.com/submissions 